National Marine

Fisheries Service

NOAA
Fishery Bulletin

a established in 1881 a
Spencer F. Baird

First U.S. Commissione of Fisheries and founder of Fishery Bulletin

\begin{abstract}
Design-based estimators, which have well known statistical properties, exist for random sampling survey designs and provide unbiased estimates of the mean and variance of summary catch statistics. Although application of these estimators to fixed-station surveys is not technically valid, they can result in unbiased differences between years if the data exhibit spatial persistence A persistent system is one in which the differences in relative abundance of a population that are recorded at fixed stations are consistent from year to year (i.e., there is no interaction between station and years in a 2 -way classification). In a fully persistent system, the changes in relative abundance derived from fixed stations will be unbiased. In this study, the persistence in relative abundance data collected from a fixed-station survey intended to monitor juveniles of economically important species is evaluated. The results can be used to infer those species for which changes in relative abundance estimated from fixed-station surveys will be more accurate than changes in relative abundance estimated from random surveys.
\end{abstract}

Manuscript submitted 24 July 2017. Manuscript accepted 20 November 2017. Fish. Bull. 116:69-74 (2018).

Online publication date: 12 December 2017. doi: 10.7755/FB.116.1.7

The views and opinions expressed or implied in this article are those of the author (or authors) and do not necessarily reflect the position of the National Marine Fisheries Service, NOAA.

\title{
The forgotten need for spatial persistence in catch data from fixed-station surveys
}

\author{
Laura M. Lee (contact author) ${ }^{1}$ \\ Jason E. Rock ${ }^{2}$ \\ Email address for contact author: laura.lee@ncdenr.gov \\ 1 North Carolina Division of Marine Fisheries \\ P.O. Box 769 \\ Morehead City, North Carolina 28557 \\ 2 North Carolina Division of Marine Fisheries \\ Washington Regional Office \\ 943 Washington Square Mall \\ Washington, North Carolina 27889
}

Sampling is essential for studying fish populations. The primary objective for many fisheries-independent surveys is to monitor the relative abundance of a population, which is an important input for stock assessments and management considerations. A wide variety of survey designs can be used to monitor relative abundance. The advantage of statistically designed surveys (e.g., stratified random) is they are associated with design-based estimators for which the statistical properties are well known. These design-based estimators are designed to provide unbiased estimates of the mean and variance (when the survey design is implemented properly).

What about fixed-station surveys? There are no design-based estimators associated with fixed-station sampling and therefore there are no estimators that guarantee unbiased statistics for these surveys. Random surveys are designed to provide an unbiased estimate of the mean, whereas fixedstation surveys, in general, provide a biased estimate; however, the magnitude of that bias could be anywhere from negligible to substantial. There is no way of determining the extent of this bias from the data themselves. Bias in any given year may be of little consequence if changes in relative abundance between years is accurately reflected by the changes in the index of relative abundance (Warren, 1994). This is determined through the property of persistence.

Persistence, in this study, is the constancy of differences in the patterns of relative abundance at fixed locations during sampling years (Warren, 1994). The greater the persistence, the greater the ability to detect interannual changes in relative abundance. In a fully persistent situation (Fig. 1A), changes in relative abundance from fixed-station surveys from year to year will be unbiased and more accurate than changes in relative abundance estimated from a random sampling design. In the case of a complex and changeable spatial pattern in relative abundance (i.e., where distribution pattern varies from year to year; Fig. 1B), a fixedstation design will result in biased estimates except in exceptional and unlikely circumstances $\left(\right.$ ICES $\left.^{1}\right)$. A randomized design leads to unbiased

1 ICES (International Council for the Exploration of the Sea). 1989. Report of the working group on methods of fish stock assessments (WGMG), 10-17 November 1989, Nantes, France. ICES CM 1990/Assess:15, 95 p. 


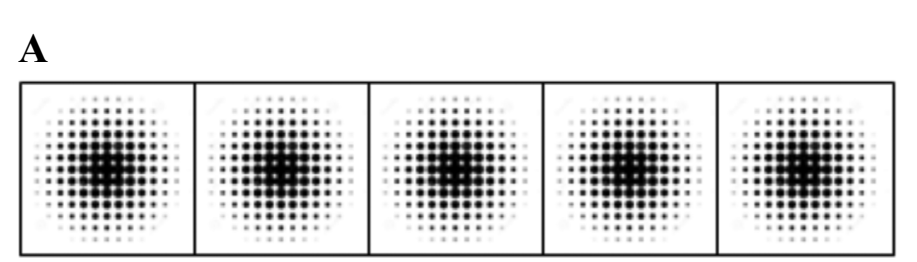

B

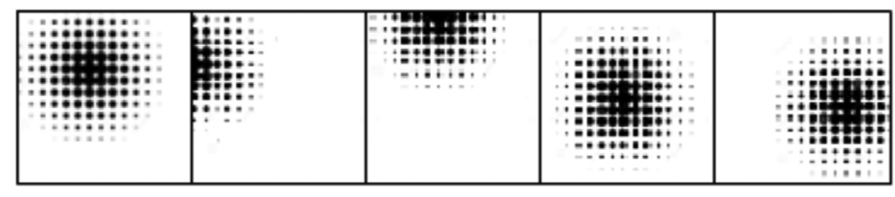

Figure 1

Simple theoretical examples of spatially (A) persistent and (B) nonpersistent catches over time. (Adapted from Houghton, 1987). Source: ICES CM 1987/D:15, 7 p. [Available from website.] border. Selection of stations was nonrandom. Major changes in sampling methods occurred in 1978 and 1989. In 1978, tow times were standardized to 1 min during daylight hours. In 1989, survey data were analyzed to determine a more efficient sampling time frame (until then sampling occurred year-round). This analysis identified a fixed set of 105 core stations and sampling was reduced to May and June only, except for July when weakfish were sampled (dropped in 1998; sampling in July was reinitiated in 2004 for spotted seatrout), and only a trawl with a $3.2-\mathrm{m}$ (10.5-ft) headrope and with 6.4-mm (0.25-in) bar mesh would be used. Each station was sampled once per month.

The current sampling gear consists of a 2-seam otter trawl with a 3.2-m headrope, 6.4$\mathrm{mm}$ bar mesh with body netting of 210/6-size twine, and a tailbag made of $3.2-\mathrm{mm}$ Deltastyle knotless nylon and with a 150-mesh circumference and 450-mesh length. Three loops of 4.8-mm (0.19-inch) chain are hung on each wing. A $4.8-\mathrm{mm}$ diameter tickler chain is used and 2 floats, each 76.2-mm (3-inch) $\times 101.6$ - mm (4-inch), are attached to the center of the headrope. The gear is towed for 1 min during daylight hours during similar tidal stages and covers $68.6 \mathrm{~m}$ (75 yards).

Environmental data are recorded during each sampling event and include depth, temperature, salinity, dissolved oxygen, wind speed, and direction. Additional habitat fields were added in 2008 . Fisheries Commission, and university researchers. The survey data have been used to characterize nursery area habitat, help designate new nursery areas, and have also been important for the federal designation of Essential Fish Habitat.

\section{Materials and methods}

\section{Data}

The NCDMF has operated the statewide Estuarine Trawl Survey, also known as Program 120, since 1971. The main objectives for the survey are to identify primary nursery areas and produce annual recruitment indices for economically important species. The survey has also been used to monitor species distribution by season and area and to evaluate environmental impact projects. The survey targets Atlantic croaker (Micropogonias undulatus), Atlantic menhaden (Brevoortia tyrannus), southern flounder (Paralichthys lethostigma), spot (Leiostomus xanthurus), summer flounder (P. dentatus), weakfish (Cynoscion regalis), blue crab (Callinectes sapidus), brown shrimp (Farfantepenaeus aztecus), pink shrimp ( $F$. duorarum), and white shrimp (Litopenaeus setiferus).

The survey samples were collected in shallow-water areas of the Pamlico Sound system in North Carolina and waters south to the North Carolina-South Carolina

\section{Analysis}

Because not all stations were sampled in May of the first year (1978) we used data collected from 1979 through 2016 and limited the analysis to those data collected from stations within the Pamlico Sound system. Only those stations sampled in both May and June over the selected period were included-a total of 29 stations for analysis (Fig. 2).

We first calculated the frequency of occurrence for each target species based on the number of tows the species was present in out of all possible tows during 1979 through 2016 (29 stations $\times 2$ months $\times 38$ years $=2204$ total tows). Indices of relative abundance were then calculated for all target species to provide estimates of trends in abundance over time. The Mann-Kendall test was applied to the indices to evaluate temporal trends. The Mann-Kendall test is a nonparametric test used to evaluate a monotonic trend in time-ordered data (Gilbert, 1987). The null hypothesis is that the time series is independent (observations are not serially correlated over time) and identically distributed (i.e., there is no significant trend across time, and therefore monotonic). The Mann-Kendall test allows for missing values and accounts for tied values when present. Mann-Kendall test statistics, including $P$-values, were calculated in $\mathrm{R}$ statistical software, vers. 3.4.2 (R Core Team, 2017) 


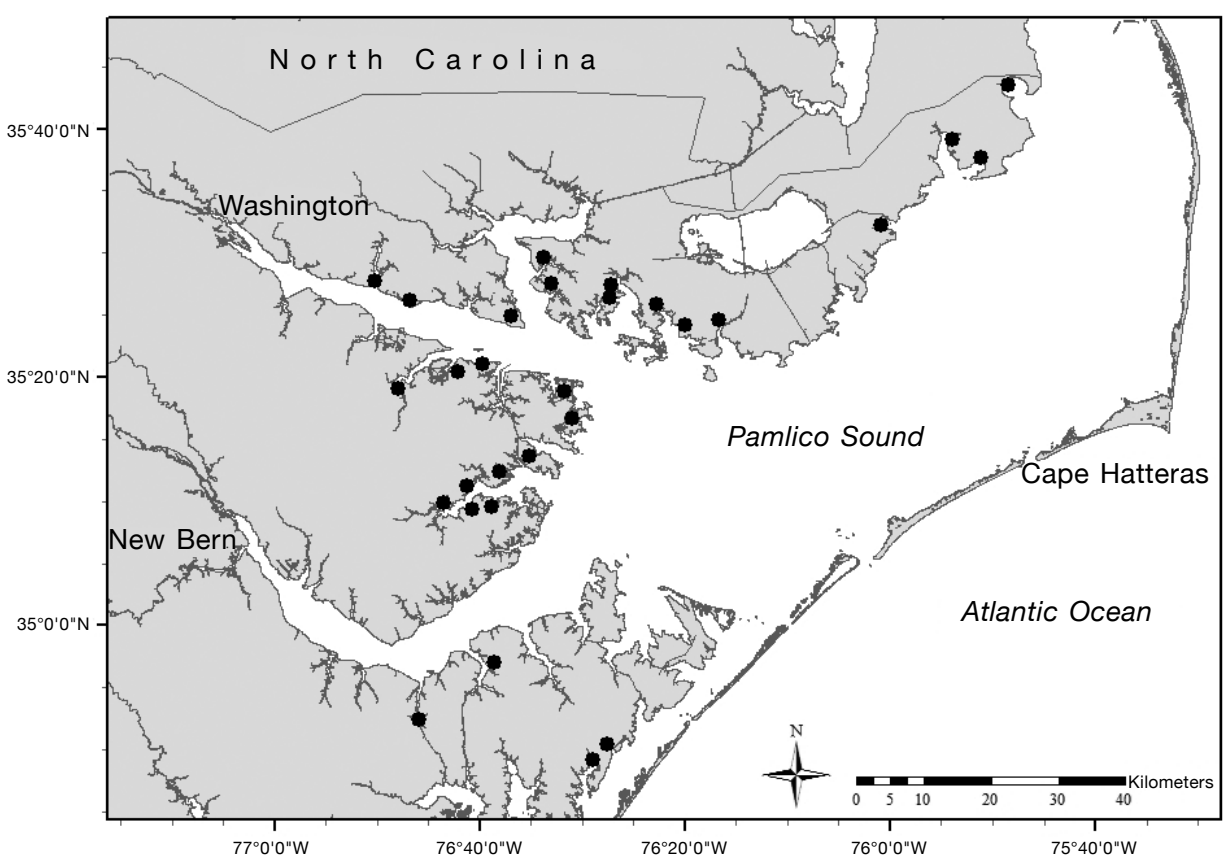

Figure 2

Map of the locations of the 29 stations $(\bullet)$ selected for use in the persistence analysis and sampled during 1979-2016 in the Pamlico Sound system in North Carolina as part of the Estuarine Trawl Survey of the North Carolina Division of Marine Fisheries.

and by using the mk.test function in the package trend, vers. 1.01 (Pohlert, 2017). Trends were considered significant at $\alpha=0.05$.

Following Nicholson et al. ${ }^{2}$, we applied a 2-way analysis of variance (ANOVA) to test the significance of the interaction of year and station for each target species. This analysis was conducted in $\mathrm{R}$ with the aov function in the stats package (R Core Team, 2017). Samples collected at the same station during May and June within the same year were considered replicates in order that the interaction term could be tested. The interaction was considered significant at $\alpha=0.05$. A significant interaction indicates a lack of persistence. Main effects were also included in the ANOVA but the results are not presented here.

\section{Results}

The target species range widely in frequency of occurrence from being present in less than $2 \%$ of tows (summer flounder) to being present in over $98 \%$ of tows (for spot) (Table 1).

The indices of relative abundance exhibit considerable interannual variability for all species (Fig. 3). Statistically significant decreasing trends were de-

${ }^{2}$ Nicholson, M. D., T. K. Stokes, and A. B. Thompson. 1991. The interaction between fish distribution, survey design and analysis. ICES CM 1991/D:11, 9 p. [Available from website.]

\section{Table 1}

Frequency of occurrence of 10 target species in 2204 trawl samples from the North Carolina Division of Marine Fisheries Estuarine Trawl Survey, 1979-2016, in the Pamlico Sound system in North Carolina.

\begin{tabular}{lcc}
\hline Species & $\begin{array}{c}\text { Number } \\
\text { of tows }\end{array}$ & $\begin{array}{c}\text { Occurrence } \\
(\%)\end{array}$ \\
\hline Atlantic croaker & 1889 & 85.7 \\
Atlantic menhaden & 1290 & 58.5 \\
Southern flounder & 1339 & 60.8 \\
Spot & 2162 & 98.1 \\
Summer flounder & 27 & 1.2 \\
Weakfish & 100 & 4.5 \\
Blue crab & 1450 & 65.8 \\
Brown shrimp & 1489 & 67.6 \\
Pink shrimp & 100 & 4.5 \\
White shrimp & 52 & 2.4 \\
& &
\end{tabular}

tected for Atlantic croaker, Atlantic menhaden, spot, and weakfish (Table 2). Statistically significant increasing trends were found for southern flounder, brown shrimp, and white shrimp. No statistically significant trends were present in the indices of relative abundance for summer flounder, blue crab, or pink shrimp. 


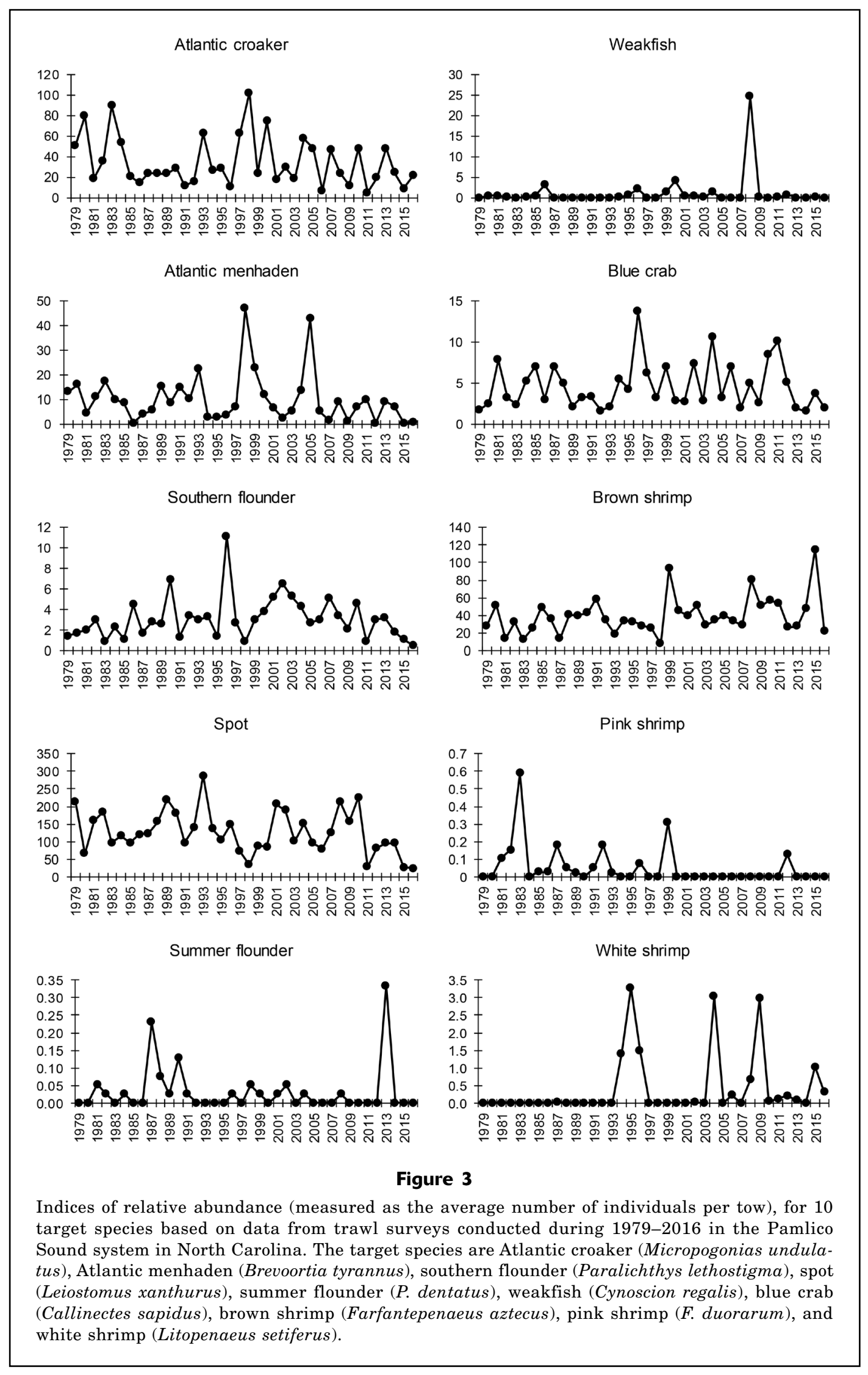




\section{Table 2}

Results of Mann-Kendall trend analyses of the relative abundance indices of 10 target species the data of which were collected from trawl surveys conducted during 1979-2016 in the Pamlico Sound system of North Carolina. $P$-values are the 2 -tailed probabilities for the trend test. The arrows in the column marked "trend" indicate the direction of the trend (decrease and increase in relative abundance over time) if a statistically significant temporal trend was detected $(\alpha=0.05)$. NS=not significant.

\begin{tabular}{lcc}
\hline Species & $P$-value & Trend \\
\hline Atlantic croaker & 0.0010 & $\downarrow$ \\
Atlantic menhaden & $<0.0001$ & $\downarrow$ \\
Southern flounder & 0.0165 & $\uparrow$ \\
Spot & 0.0104 & $\downarrow$ \\
Summer flounder & 0.1183 & $\mathrm{NS}$ \\
Weakfish & 0.0197 & $\downarrow$ \\
Blue crab & 0.9636 & $\mathrm{NS}$ \\
Brown shrimp & $<0.0001$ & $\uparrow$ \\
Pink shrimp & 0.4002 & $\mathrm{NS}$ \\
White shrimp & $<0.0001$ & $\uparrow$ \\
& &
\end{tabular}

The results of the 2-way ANOVA tests for main interaction effects indicate a lack of persistence (i.e., of statistically significant interaction) for Atlantic croaker, southern flounder, blue crab, and brown shrimp (Table 3). The data for all other target species showed the presence of persistence over the time period and stations analyzed.

\section{Discussion}

The idea of persistence made its first appearance in the primary literature in Warren's article (1994) on sampling with partial replacement. Despite the ubiquity of fixed-station surveys, the practice of testing for persistence has largely been ignored. A cited reference search (via Web of Science Core Collection) identified 7 papers that referenced Warren (1994). Of these articles, only one evaluated persistence in a fixed-station sampling survey (Li et al., 2015). Another briefly described the idea of persistence (Kimura and Somerton, 2006). Given that bias can be introduced into a relative abundance index by a lack of persistence, it seems reasonable to recommend that persistence be routinely evaluated and documented for fixed-station surveys.

The results of this study suggest that the presence of persistence is species-specific within the NCDMF Estuarine Trawl Survey. A lack of persistence was shown for Atlantic croaker, southern flounder, blue crab, and brown shrimp and indicated that this survey may be ineffective in tracking abundance for some of its target species, at least for the time series and stations

\section{Table 3}

Results of the 2-way analysis of variance tests for the year-station interaction (1036 degrees of freedom) for the period of 1979-2016 for target species collected during the North Carolina Division of Marine Fisheries Estuarine Trawl Survey conducted in the Pamlico Sound system in North Carolina. The $F$ value measures the ratio of the variance that is caused by the interaction effect to the unexplained variance. A significant interaction $(\alpha=0.05)$ indicates a lack of persistence.

\begin{tabular}{lccr}
\hline Species & $\begin{array}{c}\text { Mean } \\
\text { square error }\end{array}$ & $F$-value & $P(>F)$ \\
\hline Atlantic croaker & 5611 & 1.46 & $<0.0001$ \\
Atlantic menhaden & 6418 & 1.01 & 0.4210 \\
Southern flounder & 37.90 & 1.43 & $<0.0001$ \\
Spot & 38,524 & 0.79 & 1.0000 \\
Summer flounder & 0.15 & 1.02 & 0.3930 \\
Weakfish & 194 & 0.97 & 0.6840 \\
Blue crab & 33.79 & 1.55 & $<0.0001$ \\
Brown shrimp & 4859 & 1.26 & 0.0001 \\
Pink shrimp & 0.70 & 1.02 & 0.3950 \\
White shrimp & 6.47 & 0.93 & 0.8930 \\
& & & \\
\hline
\end{tabular}

selected for our analysis. Investigation into those life history characteristics that lead to more or less persistence may be warranted. Further examination into the spatial distribution of the catches and the changes in environmental conditions may lead to an improved understanding of persistence. The selection of stations may be species specific. For example, removal of stations where species of interest are not consistently caught may lead to improved or reduced persistence. Additionally, preliminary investigations conducted in preparation for this article suggest that choice of time series and stations can have a substantial influence on whether persistence is present.

In summary, fixed-station sampling is acceptable when random sampling is impractical, so long as persistence is evaluated and is present for the species of interest. Fixed-station surveys can be easier to implement, especially if a substantial part of the target sampling area is inaccessible to the gear. Van der Meer (1997) found that fixed-station sampling could have a higher power of detecting change over time than random sampling. In another comparison of fixed and random designs, Quist et al. (2006) found that a fixedstation design can provide a more sensitive measure of temporal variation.

How the data collected from a fixed-station survey will be used should be carefully considered. If bias in annual changes is a concern, persistence should be evaluated so that the data can be examined in context. This approach is especially important if the survey is going to be used to develop a relative index of abundance for use in a stock assessment because it is currently unknown how that bias may affect stock as- 
sessment results and subsequent management. Alternatively, one could use geostatistical modeling to produce unbiased estimates, thereby avoiding the pitfalls of applying design-based estimators to fixed-station survey data (e.g., Rivoirard et al., 2000).

\section{Acknowledgments}

The authors wish to thank 3 anonymous reviewers whose comments greatly improved this manuscript. The views and opinions in this article are those of the authors and do not necessarily reflect the position of the North Carolina Division of Marine Fisheries.

\section{Literature cited}

Gilbert, R. O.

1987. Statistical methods for environmental pollution monitoring, 336 p. John Wiley \& Sons, Inc., New York.

Kimura, D. K., and D. A. Somerton.

2006. Review of statistical aspects of survey sampling for marine fisheries. Rev. Fish. Sci. 14:245-283. Article.

Li, B., J. Cao, J.-H. Chang, C. Wilson, and Y. Chen.

2015. Evaluation of effectiveness of fixed-station sampling for monitoring American lobster settlement. N. Am. J. Fish. Manage. 35(5):942-957. Article.

Pohlert, T.

2017. trend: non-parametric trend tests and change-point detection. $\mathrm{R}$ package, vers. 1.0.0. [Available from website, accessed October 2017.]

Quist, M. C., K. G. Gerow, M. R. Bower, and W. A. Hubert. 2006. Random versus fixed-site sampling when monitoring relative abundance of fishes in headwater streams of the upper Colorado River Basin. N. Am. J. Fish. Manage. 26:1011-1019. Article

$\mathrm{R}$ Core Team.

2017. R: a language and environment for statistical computing. R Foundation for Statistical Computing, Vienna, Austria. [Available at website, accessed October 2017.]

Rivoirard, J., J. Simmonds, K. G. Foote, P. Fernandes, and N. Bez.

2000. Geostatistics for estimating fish abundance, 216 p. Blackwell Science, Ltd, Oxford, UK.

Van der Meer, J.

1997. Sampling design of monitoring programmes for marine benthos: a comparison between the use of fixed versus randomly selected stations. J. Sea Res. 37:167-179. Article

Warren, W. G.

1994. The potential of sampling with partial replacement for fisheries surveys. ICES J. Mar. Sci. 51:315-324. Article 